\title{
Renewable energy sources for rural architecture in fragile landscapes
}

\author{
G. Franco \& S.F. Musso \\ Department of Sciences for Architecture, Polytechnic School, University of Genoa, Genoa, Italy
}

\begin{abstract}
One of the main problems that can be addressed re-using and renovating the rural architecture in fragile landscape, is the research of a difficult balancing between conflicting demands. The architectural and landscape values, to be preserved and enhanced, may become a sort of obstacle to reach some kind of comfort (at least for heat and electricity) requested from new users. Insertion of new 'stand-alone' systems may cause modification not only on the perception of the landscape, but also on the physical maintenance of existing materials and structures and conservation of spaces. With specific reference to this topic, the paper deals with problems, reflections and solutions found to give new life to abandoned small settlements included in the National park of Cinque Terre, in eastern Liguria, which is also listed as UNESCO site.
\end{abstract}

\section{ENERGY EFFICIENCY AND CONSERVATION}

\subsection{Conflicts...}

The research carried out during the last ten years by the authors and published as guidelines for conservation, maintenance and enhancement of rural architecture in several Ligurian parks, regional or national (Musso \& Franco 2000, 2006, Musso, Franco \& Gnone 2008) are actually used as practical and methodological tools by owners and end users. Nevertheless, one main unresolved problem, especially for those settlements that arise on the hills far from any technical supply (as electric net, water and gas) regards the possible ways to reach an acceptable level of comfort inside and outside the buildings, even recurring to new technologies and renewable sources. The fact that most of these parks are protected by national and regional laws has repercussions on the process of authorization of new technical installation by all the institutions in charge of the safeguard of landscape and architectural values, that don't follow, up to now, unified criteria.

Mainly for these reasons, the Regional Directorate of Liguria for Cultural and Landscape Property presented a research project focused on the definition of guidelines to improve the eco-efficiency of the scattered rural buildings located in the UNESCO site of Cinque Terre, preserving their architectural and landscape values. The research programme has been financed through the funds explicitly issued by the Italian state to cover projects and studies for the management of the Italian World Heritage proper- ties. The Universities of Genoa and Pavia have been selected to develop the research and verify the real applicability of systems for the eco-efficiency of the buildings and their compatibility with the landscape values.

This is one of the first cases developed in Italy, beyond few experiences and two other guides edited by the same Ministry (Di Bene \& Scazzosi 2006; Baldesco \& Barion 2011), and testifies the extreme attention that technicians in charge of safeguard of cultural heritage pose to the issues concerning environmental sustainability of historical heritage, aimed at overcome a series of technical difficulties and cultural constraints.

Improving energy efficiency of traditional architecture more constraints and limits than opportunities clearly emerge. They are, for example, limits imposed by the imperative demand to not alter cultural and material values (not all the available technical solutions are acceptable for they can potentially destroy historical architectures), or limits imposed by the economic capacity of the owners. In the meantime, other limits derive from the specific authorization processes to be followed, under responsibility of institutions devoted to the safeguard of the historical heritage which generally do not consider any problem related to energy efficiency and do not easily accept contemporary technical solutions. The peculiarity of traditional architecture excludes any form of standardization, often linked to the application of technical devices. Furthermore, the complexity and unpredictability of any intervention of restoration/renovation of historical structures often 
generate a number of unexpected and risky situations which can slow down the whole process and impose several reiterations and modifications of the project.

The enhancement of energy behaviour of traditional architecture is often reached just inserting new parts in substitution of the old ones. In many cases new components (windows, insulation materials, boilers, lighting, etc.) are independently designed and installed, serviced and maintained by different professionals and companies without a comprehensive view and understanding of the building as a whole and of the historical context which it belongs to. The consequences could be, on one hand, the superimposition of the modern technical approach (with consequent lack of conservation) and, on the other hand, the cultural distancing of experts in conservation and valorisation of architectural historical heritage. A cultural gap between these two categories of experts could deepen and this is not at all desirable nor useful.

The historical heritage may be considered a repository of valuable 'reusable resources' and its integrated conservation can extend their active life in reasonable future economic conditions. But historical architectures are at the same time 'non-renewable resources' and therefore the interventions should be able to cope with specific conflicts of interests, as the achievement of new requirements for modernisation and integral conservation.

On the other hand it is not always necessary, or possible, to comply with modern comfort standards and regulations and some distance from these technical requirements can thus be accepted. It is also dangerous to force the renovation project to whatever use and it should be much more profitable (for cultural and economic reasons) to adapt the use to the building characteristics previously determined.

\section{2 ...And opportunities}

It is the right time to start providing answers to all the raised questions, even in terms of historical heritage destiny. However, the risk of an excessive attention to technical details, that threatens to promote the primacy of the idea of the 'new' at all costs, or simply to save fuel consumption, is here under attack. The relationship between technological innovation and architectural and environmental research is still largely a process of the simple application of products and technologies or, in other words, of applied science, which does not constitute real innovation. This often leads to an unbalanced and risky relationship and to a greater emphasis on just the technical components that do not correspond to effective cultural advancement. Neither do they improve the capacity to assimilate and modify the technology to achieve higher long-term objectives.

Contemporary age often confuses technological innovation with the social utility of techniques which they need to solve problems, therefore contributing to a vision of technology assumed to have total and absolute value (Staudenmaier 1985).

It is mainly for these reasons that the cultural heritage sector, more slowly than others, is giving more weight to the importance of environmental technologies. This might even play a key role beyond the boundaries of the specific disciplines of conservation, in the reporting of the discussions and research on a less reductive and more conscious plan for the various implications that the issues they raise have for the human environment, now and in the future.

This may contribute to an ever more necessary overturn in the objectives and cultural references which until now have been considered exclusive. Apart from the issue of conservation of resources the concern for the protection of historical and architectural goods and the importance of suggesting research into new forms of compatibility may be pushed to the foreground.

The culture of conservation, in the broader sense, clearly and urgently brings to the surface a set of values which help to bring back into the technical sphere the importance of understanding its role as a means and not as an ultimate end in itself. Nevertheless, the lateness with which the cultural heritage sector in its entirety has dealt with the issue of environmental sustainability can be transformed from a weakness into a point of excellence concerning, for example, the possible integration into the buildingplant system of renewable energy sources, primarily sun, wind and geothermic. The aspiration is here for quality, not only in terms of fuel savings but also to open up the way for previously unpublished researches on the integration of plant systems.

However, the integration of new plant devices with new technology raises other considerations concerning the relationship between conservation, innovation and design.

The ever more frequent adoption of innovative technology and equipments powered by renewable energy sources within projects of conservation and redevelopment of historical buildings and districts, brings into focus the necessity for a new creative approach. This should be developed in different forms from that which is commonly accepted at present.

Creativity can be expressed through the design of components which can be more easily integrated within traditional architectures. This can go hand in hand with the most recent experiments in the field of new materials, for example in the production of organic solar cells, or thin film which can applied to different supports and act like a photograph printing process, or elements in solar cells put on a non rigid membrane and therefore better adapted for the production of awnings and other additional elements (Franco 2012). 


\section{GUIDELINES FOR ECO-EFFICIENCY OF RURAL ARCHITECTURE}

\subsection{Principles and methodology}

The tools allowing for the preventive control of interventions in the form of guidelines have, for several years now, demonstrated an effective synthesis of the action taken by participating administrators and technicians - from owners to investors, developers and users (Advisory Council on Historic Preservation 2011; Canada's Historic Place 2010; Changeworks Edinburgh World Heritage; Advice Series Ireland 2010; Grimmer et al. 2011; The Vancouver Heritage Foundation, U.S. Department of Energy 2011). A guide dedicated to the enhancement of rural architecture according to the principles of environmental sustainability can above all act as a stimulus and promotion of a cultural behaviour that should be shared among both the administration and the community.

The study of architectural, material, structural and morphological characteristics represents the basis upon which to construct an information system concerning the state of conservation and the durability of materials and components, as well as stability, liveability, effectiveness and efficiency. Compared with the information acquired to prepare guidelines for conservation and maintenance (Musso \& Franco 2006) more data on the behaviour and energy efficiency of materials and components needs has been collected and assessed (information for plant design, which should be calculated theoretically in relation to building features, climatic conditions and exposure and in comparison with available data on fuel consumption of similar buildings).

Beyond the technical help (mainly in calculation) the new guide for eco-efficiency of traditional rural buildings faces the problem of the compatibility and permissibility of interventions, especially concerning renewable energies. As a matter of fact, laying out criteria for the admissibility of interventions represents a methodological issue which needs to be solved in a clear manner, sharing some conservative principles that go further the technical feasibility.

The clarification of these criteria (where technical interventions are considered permissible and where not) follows the identification of possible technical solutions to problems of thermal insulation of the external seals, both opaque and transparent (ground floors, walls, doors, windows and roofs), with particular attention to the window systems. The ecoefficiency of the building must not exclude the plant efficiency and must also consider micro-generation (water systems and the supply of water, heat, cooling and lighting). Integration of renewable energies should therefore allow for a consistent saving of resources but should not neglect to consider the possibly invasive effect of new work on existing buildings.
On these bases, the work has been developed following some general principles, as:

1. Effective management of natural resources (rainwater collecting and water recovery through integrated herbal depuration, wind, sun, biomass) in relation to territorial vocations, on one side, and conservation of traditional materials and structure, on the other.

2. Conjugation of aesthetic perception with scientific research, by setting up reliable calculation methods to assess the real energetic behaviour of rural architecture, which must not comply with energetic standards.

3. Ability to verify/repeat necessary energetic audits for other buildings within the World Heritage property or to relate correctly to the representative case studies, so as to help the user read the analytical results.

4. Adopting simple methodologies, available on the market and economically sustainable, with regard to costs/benefits ratio, explicating the most advantageous conditions so as to orient the choice of different installations, including those exploiting renewable resources.

5. Maintaining/repairing rather than substituting, especially when the installation of new technical devices becomes necessary, aiming to a real architectural and landscape compatibility, assuming the conservation of the building and its components as one of the fundamental criteria for the admissibility of the interventions.

6. Aspiring to a constructive dialogue between technical innovation and architectural enhancement, focusing on sensitivity and creativity.

\subsection{Phases of the research}

Specifically, the study has been articulated in the following phases, set up at the intervention level scale, from the territorial one to the architectural detail level (De Marco, Franco \& Magrini 2013; Franco \& Magrini 2013; Franco 2013). These phases have been developed in parallel and integrated as follows.

1. A systemic landscape analysis of environmental resources, territorial vocations and sensitivities; the identification of settlement systems and of the recurrent building morphologies, in order to select three different case studies (the single-cell building, the multiple-cells building, the country house).

2. The analysis of the thermal characteristics and of the energetic needs of the scattered rural built heritage (starting from the three case studies) and the identification of criticalities due to settlement and constructive features.

3. The identification of the technical operations to improve energetic performance of buildings (thermal insulation and heating systems) and definition of architectural compatibility and non- 
compatibility criteria to ensure the respect of traditional building features.

4. Quantification of energetic savings of the adopted solutions (evaluated in a combined manner).

5. Definition of landscape compatibility criteria for the insertion of renewable energy technologies.

\subsection{Beyond the disciplines}

Following the strong concept underpinning such a kind of project, it is necessary to loosen some of the methodological and technical bonds in order to overcome the segmentation of competencies, which up until now have been playing in this sector. On the occasion of this first important research it has been formed, within the Department DSA, a really interdisciplinary group around the following competences. Experts in architectural survey are specializing in using different methods and tools and testing their validity through the application (topographic, analytical and digital photogrammetry, rigorous direct measurement, digital laser scanning). Experts in architectural conservation/restoration, the core of the research group, develop analysis/diagnosis on constructive materials and techniques, structural behaviour and assessment, morphological analysis, diagnosis of decay phenomena even through noninvasive technologies, identification of suitable techniques of intervention, restoration works. Experts in environmental assessment and energy audit on historical building are now developing an evaluation methodology that takes into account also the tangible and intangible architectural values to find a balance between energy optimization and saving and cultural values and needs. Experts in research and development of innovative technologies and renewable energies are able to individuate, together with the other experts above mentioned, a strategy to optimize energy consumption, carefully considering also constructive features, climatic conditions and architectural values.

\section{SPECIFIC RESULTS OF THE RESEARCH}

On the base of the knowledge acquired along the years, the research has been focused on the three sample cases which are representative of the territorial system, of the settlement morphologies (aggregated houses, rural buildings, isolated structures) and of the constructive technologies, with special attention to the most vulnerable heritage.

At the territorial scale and for the different settled areas, resources, vocations and sensitivities (orography, exposition, superficial and profound petrology, land use, presence of terraced systems, accessibility....) have been examined in order to choose the installation typologies most adapt to be integrated with natural resources (water, sun, biomass).
The analysis of climatic and geomorphologic conditions, carried out on more numerous sample sites, has aimed at understanding the effective applicability of innovative technologies for individual production and energy consumption (solar panels, photovoltaic panels, geothermal or hydrothermal installations, biomass, heat pumps...). Also at this level the importance of landscape and architectural value has been taken into consideration. The problem of improving the energy efficiency and production for residential use, agricultural production or in tourist facilities has been framed in a systemic manner, highlighting the relations among different systems (geo-morphological, climatic, environmental, constructive ...) and identifying the possible solutions and the consequences of their application so as to optimize the relation among systems rather than maximize the use of one in respect to others.

At the territorial scale, the most significant public paths and panoramic views have been identified, with special regard to famous or traditional views which have become part of the collective imaginary of these places, so as to assess the impacts of the most recurrent interventions on the landscape.

The calculation of the energy performances of the sample buildings has been carried out taking into account the climatic conditions of the localities in which they are situated. As for the indoor temperature of the analysed buildings, as requested by the procedures foreseen by the technical norm UNITS 11300 part 1 - Determination of the thermal energetic exigencies of the building for its summer and winter air conditioning, a winter temperature of $20^{\circ} \mathrm{C}$, constant along the 24 hours, has been adopted as project data. For the calculation of the average monthly external temperature, an interpolation is necessary, as indicated by the norm UNI 10349 Heating and air conditioning of buildings. Climatic data, of the data concerning the province of La Spezia, within which the selected municipalities are located. Assuming as hypothesis low-efficiency technical installations, in relation to the examined case studies, the theoretical global performance index of the buildings has been determined and associated to the energetic class of the building - installation system for winter air conditioning and hot water production.

An overview of interventions for thermal improvement has been elaborated, including the adoptable technical solutions (insulation systems and installations for the production of hot water through solar energy, for the winter/summer air conditioning through heating pumps and biomass, for the production of electric energy and the recycle of rainwater). For these interventions, the impacts on the architectural system - i.e., possible modifications to the constructive system due to the real modalities of application of insulation technologies - have been assessed, and their effectiveness, in terms of re- 
source saving, compared to the reduction of volumes and surfaces, caused by insulation systems.

For the critical points of the buildings, source of thermal dispersion and humidity infiltration, the most compatible insulation solutions have been indicated and the most suitable technical systems, also in terms of economic sustainability, have been identified. Alternative combined solutions for the building and the installation system have been evaluated, through the selection of different types of insulating products and of different thickness (verifying the formation of interstitial condensation and surface mould), and the results have been synthesized in graphics illustrating the percentages of improvement for the energetic performance indexes of the envelope for the alternative solutions.

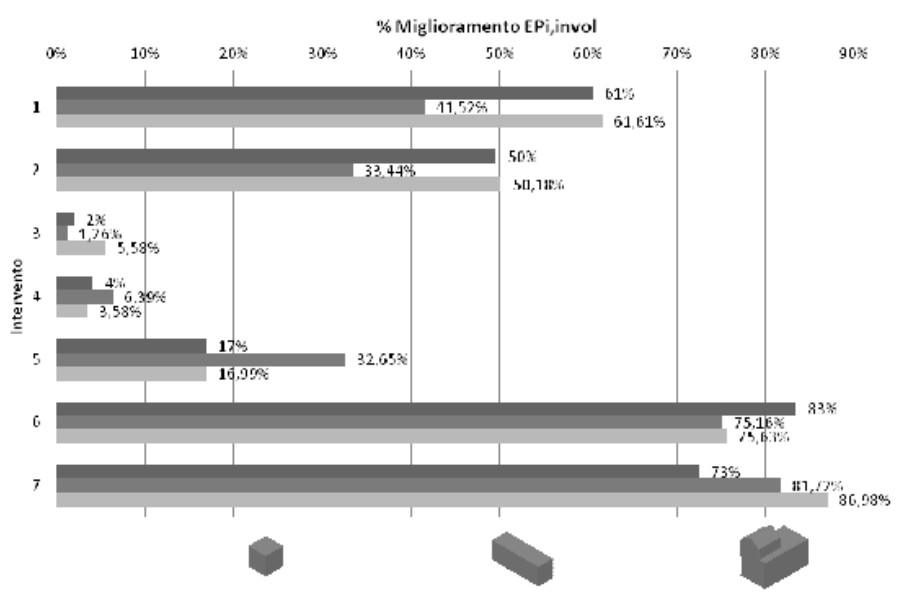

Figure 1. The chart summarizes the percentage of thermal improvements related to different types of interventions, indicated in the ordinate axis. 1 . Insulation of the walls $10 \mathrm{~cm}$; 2 . Insulation of the walls $4 \mathrm{~cm} ; 3$. Replacement of windows; 4 . Insulation of the ground floor; 5. Insulation of the roof; 5. Combination of interventions $(1+3+4)$; 6 . Combination of interventions $(2+3+4)$. In the three rows corresponding to each type of intervention are indicated the results for each case study, respectively the single-cell building (high row), the multiple cells building (middle row), the country-house (low row)

Departing from an energetic demand as high as $300 \mathrm{kWh}$ (square meter per year), corresponding to an energetic class $G$, it is possible to reach very efficient energetic classes, if the rehabilitation encompasses integrated actions on the envelope and on the technical systems through the use of renewable energetic resources.

The interventions have a different percentage incidence according to the examined configuration and on the base of its geometric and structural features. In particular, for the multi-cellular configuration, interventions on the roof result more effective than the solutions foreseeing the insulation of the walls, in relation to the higher bearing of the horizontal surfaces in this type of buildings.
On the contrary, for single-cell configurations and rural buildings as country-houses, the insulation of the walls appears more advantageous, in that they weigh on more on the global envelope surface.

Also in the case of transparent envelopes, substantially different percentage of improvement are registered in relation to the percentage of window surface out of the global building envelope; in particular, substituting the windows with new ones appears more advantageous for manor houses, which is featured by a window surface wider than the other configurations.

One specific part of the research has been developed taking into consideration the problem of energy micro-generation, considering that most of the abandoned rural buildings are completely isolated from any supply system. Working on real cases to be reused, different strategies of micro-generation and cogeneration have been considered, identifying technical and architectural advantages and disadvantages for each of them (biomass, co-generation, energy generation through wind and sun).

Finally, the criteria of landscape compatibility for devices fed by renewable energetic resources have been made explicit also through photo-simulation. Compatibility depends on location (in respect to the territorial vocations and the panoramic views), quantitative factors (according as they are isolated or repeatable/aggregated systems, on the base of the covering of the soil or orography) or qualitative factors (i.e., device morphology, colours, possibility of visual impact mitigation).

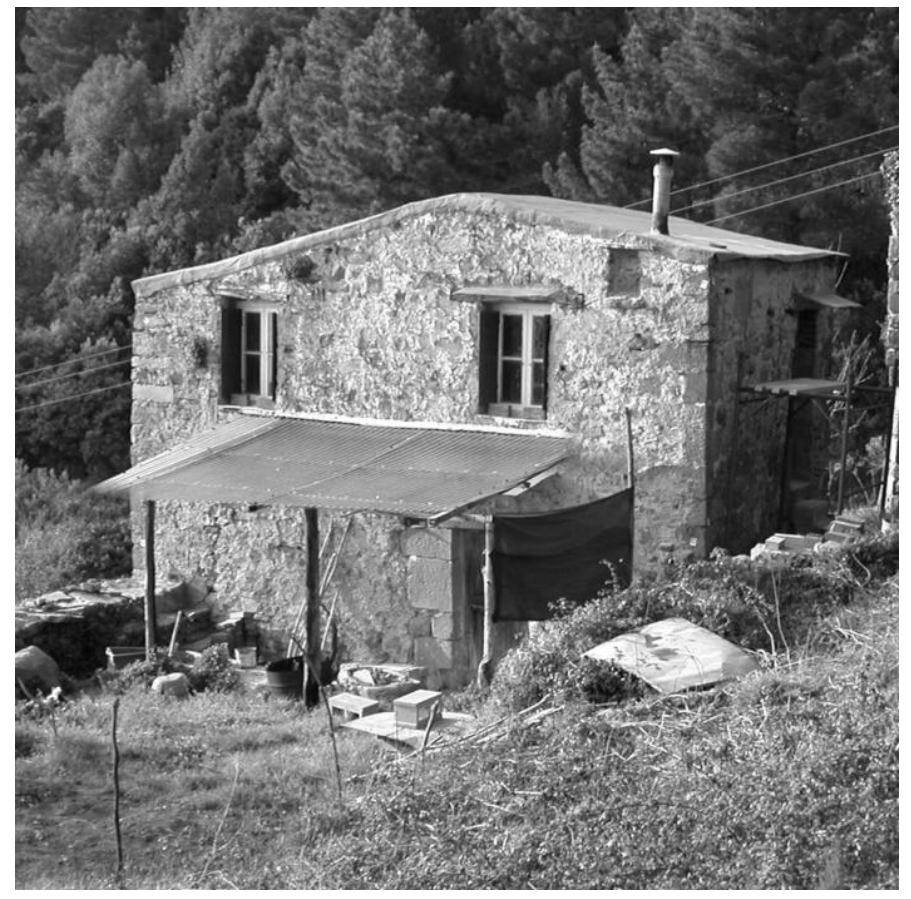

Figure 1. The image represents a traditional rural building in Cinque Terre National Park, where a plastic shelter has been inserted in front of the main door to protect from rain and sun 
The impacts have not been assessed only from a perceptual point of view: an important role is also played by the state of conservation of building materials and systems subject to intervention, the possible removal of traditional materials, the level of invasiveness of the structure on the ground and on the terraced system. Photo-simulations visualise possible interventions integrating solar technologies with traditional roofing (in case of complete replacement due to advanced structural deficiency, in agricultural or residential service structures, in projecting roofs, in improper existing additions) so as to build the richest picture of possible interventions to be considered admissible or, on the contrary, unacceptable.

The compatible insertion of innovative technical systems that can be integrated, possibly on added components, rather than on traditional roofs, pose in the foreground the role of creativity, in mimetic or contrasting forms.

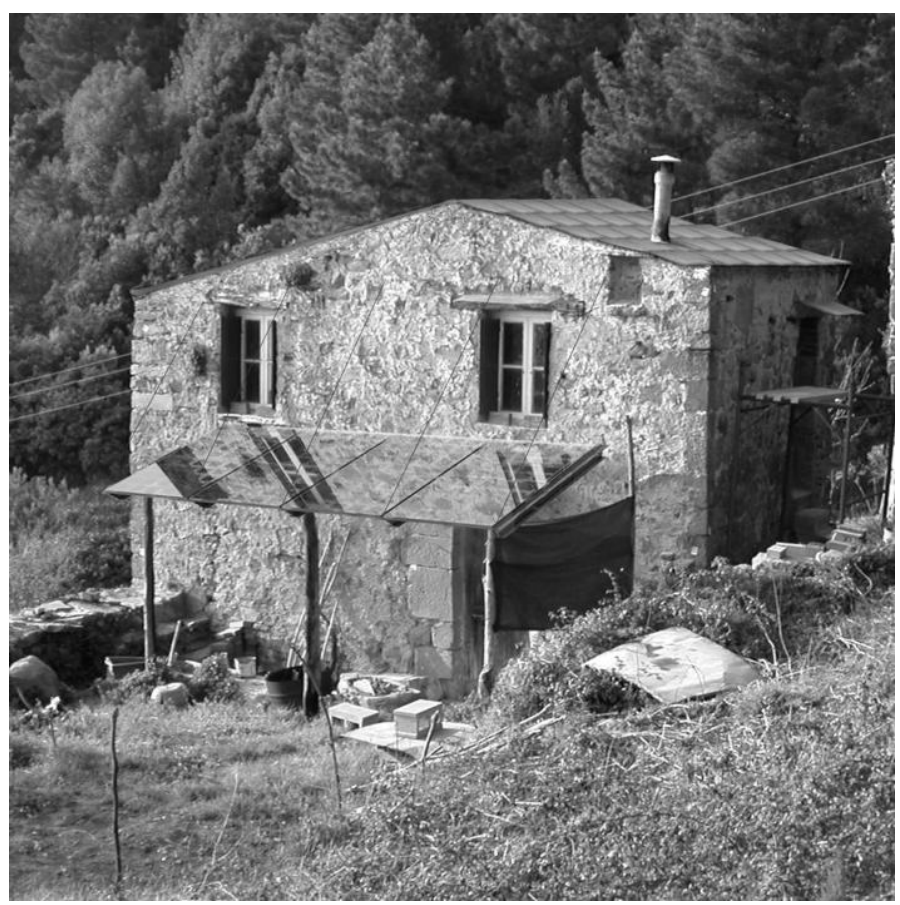

Figure 2. Photo-simulation on the same building of Figure 1. The plastic shelter has been substituted with a glass photovoltaic one for energy generation

\section{NOTE}

The research has been developed by an interdisciplinary group constituted around the Universities of Genoa and Pavia. Personnel belonging to department DSA, Genoa, is: prof. Giovanna Franco and prof. Stefano F. Musso, architect Antonella Serafino, expert in environment technologies, arch. Guglielmo Parodi, expert in rendering, ing. Marco Cartesegna, expert in technical plants, arch. Marco Guerrini, expert in energy audits. Personnel belonging to the University of Pavia is prof. Anna Magrini, expert in Building Physics, energy audits and scientific responsible for energy calculations and ing. Roberta
Pernetti, expert in dynamic thermal evaluation. Scientific responsible of Regional Directorate for Guidelines for eco-efficiency in the UNESCO site is arch. Luisa De Marco, Regional Director is arch. Maurizio Galletti.

\section{REFERENCES}

Advisory Council on Historic Preservation, 2011. Sustainability and historic federal buildings, Washington, D.C.

Baldesco, I. \& F. Barion, F. (Eds.), 2011. Fotovoltaico: prontuario per la valutazione del suo inserimento nel paesaggio e nei contesti architettonici, Direzione Regionale per i Beni Culturali e Paesaggistici del Veneto.

Canada's Historic Places, 2010. Standards and Guidelines of Historic Places in Canada, 2nd ed.

Changeworks, Edinburgh World Heritage (no date). Energy Heritage. A guide to improving energy efficiency in traditional and historic homes.

Energy Efficiency in Traditional Buildings, 2010. Ireland: Advice Series.

De Marco, L. et al. 2013. Guidelines for eco-efficiency in the UNESCO site of Cinque Terre: an example of best practice. In Boriani, M. (Ed.), Built Heritage 2013, Monitoring Conservation and Management: 9-16. Milan: Centro per la Conservazione e Valorizzazione dei Beni Culturali.

Di Bene, A. \& Scazzosi, L. (Eds.), 2006. MIBAC, Gli impianti eolici: suggerimenti per la progettazione e la valutazione paesaggistica. Roma: Gangemi Editore.

Franco, G. \& Magrini, A., 2013. Eco-efficienza del patrimonio storico in un paesaggio culturale, in Lucchi, E. \& Pracchi, V. (Eds.), Efficienza energetica e patrimonio costruito. La sfida del miglioramento energetico nell'edilizia storica: 231-247. Milano: Maggioli editore.

Franco, G., 2013. Innovazione e sostenibilità in un paesaggio culturale, Technè 5:129-134.

Franco, G., 2012. Sustainability and Heritage: a challenge for contemporary culture. In Crisan, R., Kealy, L., Musso, S.F. \&, Franco. G. (Eds), Conservation/Regeneration: The Modernist Neighbourhood: 443-467. Leuven: EAAE Transactions on Architectural Education (58).

Grimmer, A.E. et al. 2011. The Secretary of the Interior's Standards for Rehabilitation \& Illustrated Guidelines on Sustainability for Rehabilitating Historic Buildings. Washington, D.C: U.S. Department of the Interior National Park Service.

Musso, S.F. \& Franco, G., 2000. Guida alla manutenzione e al recupero dell'edilizia e dei manufatti rurali. Venezia: Marsilio Editori.

Musso, S.F. \& Franco, G., 2006. Guida agli interventi di recupero dell'edilizia diffusa nel Parco Nazionale delle Cinque Terre. Venezia: Marsilio Editori.

Musso, S.F. et al. 2008. Architettura rurale nel Parco del Beigua. Guida alla manutenzione e al recupero. Venezia: Marsilio Editori.

Staudenmaier, J.M., 1985. Technology's Storytellers. Reweaving the Human Fabric. Boston: The Massachusset Institute of Technology.

The Vancouver Heritage Foundation (no date). New life Old Buildings. Your green guide to heritage conservation.

U.S. Department of Energy, Pacific Northwest National Laboratory \& Kaufman Heritage Conservation, 2011. Energy Performance Techniques and Technologies: Preserving Historic Homes. 